\title{
LET'S ASK THEM: A NATIONAL SURVEY OF DEFINITIONS OF QUALITY OF LIFE AND ITS ENHANCEMENT AMONG PEOPLE AGED 65 AND OVER*
}

\section{ANN BOWLING \\ ZAHAVA GABRIEL \\ JOANNA DYKES \\ LEE MARRIOTT DOWDING}

University College London

\section{OLGA EVANS}

Office for National Statistics, London

\author{
ANNE FLEISSIG \\ DAVID BANISTER \\ University College London \\ STEPHEN SUTTON \\ University of Cambridge
}

\section{ABSTRACT}

This study aimed to explore older peoples' definitions of, and priorities for, a good quality of life for themselves and their peers. Nine hundred and ninety-nine people aged 65 and over, living at home in Britain, were interviewed for the study. Good social relationships were the most commonly mentioned constituent that gave respondents' lives quality (mentioned by 81 percent). Other important factors were social roles and activities, health,

\footnotetext{
*Those who carried out the original analysis and collection of the data hold no responsibility for the further analysis and interpretation of them. Material from the ONS Omnibus Survey, made available through ONS, has been used with the permission of the Controller of The Stationery Office. The dataset will be held on the Data Archive at the University of Essex. The research was funded by the Economic and Social Research Council (award no. L480254003; Quality of Life). The Quality of Life Questionnaire was also part-funded by grants, held collaboratively, by Professor Christina Victor and Professor John Bond (L480254042; Loneliness and Social Isolation, also part of the ESRC Growing Older Research Programme), and by Professor Shah Ebrahim (Medical Research Council Health Services Research Collaboration (Health and Disability) and the authors are grateful for their support.
} 
psychological outlook and well-being, home and neighborhood, finances, and independence. Poor health was most often mentioned as taking quality away from life (by 50 percent). Social relationships and health were judged to be the most important areas. Having health and enough money were the two most frequently mentioned things that would improve the quality of their own lives and those of their peers (though in different order of magnitude). The need for dynamic, multidimensional, and integrated models of quality of life in older age is suggested by these results.

This article presents the results of a national survey of people aged 65 and over living at home in Britain, which aimed to investigate their definitions of, and priorities for, a good quality of life. The study is significant because it provides empirical data on which theoretical models and measures of quality of life can be judged in terms of their content validity.

The concept and measurement of quality of life are dependent largely on expert rather than lay views of the important constituents (Bowling, 2001; Rogerson, Findlay, Coombes, \& Morris, 1989). Investigation of lay views is essential if the current body of knowledge on the constituents of this complex concept is to be developed, if measurement scales are to have any relevance to people and their everyday lives, and if public policies which affect life quality thereby influenced. To this effect, Fry (2000) has suggested that the goal of research on quality of life can no longer be to simply generate group level data drawn from ratings of life satisfaction nor to confine research to case studies, but to create a composite picture which allows respondents to express their meanings alongside more traditional quantitative approaches, and leads to an interdependent "reflexivity" between researchers and participants in research.

Alongside this new approach to quality of life research is a change in the conceptualization of older age. While for some people, older age will be a time of increasing dependency and loss of control, many people in the fourth age are independent, and engage in everyday activities without restriction. Despite variations in health, and also in social circumstances which can influence the experience of ageing (Grundy \& Bowling, 1997), most people of this age report that they are happy and satisfied with their lives (Bowling, Farquhar, \& Browne, 1991; Bowling, Farquhar, Grundy, \& Formby, 1993; Walker \& Maltby, 1997). Philosophers long ago recognized that older age also contains many opportunities for positive change and productive functioning, and should not be confused with illness (Cicero, 44BC, reprinted 1979).

There is international interest in the constituents and enhancement of quality of life in older age. This is partly due to the increasing numbers of people aged 65 and over and higher expectations of society, and to policy interest in the potential for reducing public expenditure. The societal costs of ageing could, in theory, be reduced by enabling older people to retain their independence for 
longer, thereby also enhancing their quality of life. At the same time, the hypothesized future compression of morbidity and disability into a shorter period of life is leading to more positive perspectives of healthy ageing as normal (Bowling, 1993). Rather than fostering dependency, future public policy is likely to be concerned with empowering older people to maintain their active contribution to society, and to respond effectively to the physical, psychological, and social challenges of older age.

\section{MODELS OF QUALITY OF LIFE}

Quality of life (QoL) is a multi-level and amorphous concept which reflects both macro societal and socio-demographic influences and also micro concerns, such as individuals' experiences, circumstances, health, social well-being, values, perceptions, and psychology. It is thereby a collection of interacting objective and subjective dimensions (Lawton, 1991). It is dependent on the perceptions of individuals, and is likely to be mediated by cognitive factors. However, models of quality of life are not consistent. Some incorporate a needs-based satisfaction model, based on Maslow's (1954) hierarchy of human needs for maintenance and existence (physiological, safety and security, social and belonging, ego, status and self-esteem, and self-actualization). Scales used to measure the quality of life of people with mental health problems, for example, are based on a satisfaction of human needs model, coupled with assessments of global well-being (Bowling, 2001). In contrast, traditional social science models of quality of life, have been based primarily on the overlapping concepts of "the good life," "life satisfaction," "social well-being," "morale," "the social temperature," or "happiness" (Andrews, 1986; Andrews \& Withey, 1976; Larson, 1978). This reflects the influence of early Greek and 19th century utilitarian philosophy, with their focus on well-being, happiness, pleasure, and satisfaction. However, while overlapping to some extent, quality of life is conceptually distinct from well-being and satisfaction (Spiro \& Bossé, 2000).

Social gerontologists, particularly in the United States, have focused more on retention of independence, social activity, growth, control over life, social role functioning, cognitive competence, adaptability, and morale and life satisfaction as key constituents of quality of life (Andrews, 1986; Baltes \& Baltes, 1990; Day, 1991; Fry, 2000; Larson, 1978; Lawton, 1996). Of these, morale and well-being have been most frequently explored, generally defined in terms of life satisfaction and self-esteem. They are most commonly measured using scales of overall life satisfaction, sometimes supplemented with narrower scales of psychological morbidity, in particular of depression and anxiety (Bowling, 1997; Wenger, 1992). While the importance of self-mastery or control over life, autonomy (freedom to determine one's own actions or behavior) and independence (the ability to act on one's own or for oneself, without being controlled or dependent on anything or anyone else for one's, functioning) have been 
emphasized by investigators (Baltes \& Baltes, 1990), and by samples of older people (Fry, 2000), they have been less frequently measured systematically.

In Britain and the rest of Europe, a main focus of social research has traditionally been influenced by the positivist perspective of functionalism, and has thereby encompassed the more negative issues of dependency, poverty, service use and needs, and declining physical and mental health (Bowling, 1993). Clinical gerontology has similarly adopted a negative pathology model as the norm for old age, and assumes that it is a time of physical, social, and psychological decline. The care needs of dependent older people have been emphasized at the expense of rehabilitation, prevention, and curative treatment once medical problems have been detected (Roos \& Havens, 1991). Research based on this model inevitably under-estimates the quality of life of older people.

The largest body of empirical research on the various facets of well-being has focused on the structure of social networks and the functioning and supportiveness of human relationships. Despite inconsistencies, probably due partly to wide variations in measurement scales used, fairly strong evidence appears to exist of associations between social support, network structure and mortality, and mental and physical health status and well-being (Bowling, 1994; Bowling \& Grundy, 1998). There are similarly long established associations between social participation and/or support and feelings of security, self-esteem, and hence self-mastery, especially if relationships are reciprocal, and a balance between dependence and independence is retained (Lawton, 1980; Wenger, 1992; Wentowski, 1981). Much of this literature indicates that social relationships and activity per se appear to confer health benefits through psychosocial pathways. Given that the characteristics of the neighborhood can constrain friendships and involvement in social activities, neighborhood is also theoretically associated with well-being of older people (Berkman \& Glass, 2000). However, the concepts of social cohesion, or the connectedness and solidarity between groups, and wider social capital are only just beginning to be measured by social scientists in relation to health and older age. Definitions of social capital range from references to a person's own personal social resources (perceived social network structure and support) (Bowling, 1994; Bowling \& Grundy, 1998; Sherbourne \& Stewart, 1991) to external social capital covering access to societal, environmental, and neighborhood resources (such as local facilities for leisure and social activity, which facilitate reciprocity, trustworthiness, neighborliness, safety, and social involvement (Cooper, Arber, Fee, \& Ginn, 1999; Putnam, 2000).

The most frequently reported empirical associations with both well-being and quality of life in older age are good health and functional ability, a sense of personal adequacy or usefulness, social participation, the existence of friends and social support, and level of income (Bowling, Farquhar, \& Grundy, 1996; Kushman \& Lane, 1980; Lowenthal \& Haven, 1968; Maddox, 1963; Markides \& Martin, 1979; Usui, Thomas, \& Durig, 1985). This literature also indicates overall that subjective self-ratings of psychological well-being and health are 
more powerful than objective economic or socio-demographic indicators in explaining the variance in quality of life ratings (Bowling \& Windsor, 2001).

The complexity of the concept of quality of life has lent support to phenomenological perspectives which hold that quality of life is dependent upon individual perceptions and cannot be defined or measured using traditional measurement scales. Thus, several approaches to individualized measurement have been developed based on open ended questions asking people to identify, prioritize, or weigh the important areas of their generic or health-related quality of life (Bowling, 1995a; Garratt \& Ruta, 1999; Hickey, O'Boyle, McGee, \& Joyce, 1999). There has been little research on whether they lead to any improvement in validity (Fitzpatrick, 1999).

Research on people's values shows, however, that people within a society do share a common set of core values, although these vary in their relative importance to individuals (Bowling, 1995a, 1995b, 1996; Farquhar, 1995). The literature referenced here indicates that people's values include the meeting of past expectations, their ability to cope, having their independence and control over life, a positive outlook, having good health and close others having good health, good relationships with family, friends, and neighbors, having and enjoying work, adequate finances and standard of living, and participation in social and leisure activities. Different subgroups of the population have also been reported to prioritize different areas of life as important, with older people being the most likely to prioritize their health and ability to get out, and younger people being more likely to prioritize work and finances (Bowling, 1995a, 1995b).

The definition and measurement of quality of life need to be sensitive to the differing values of different social groups, and also to value changes in response to life and health events ("response shift"). It is only by more thorough exploration of people's perceptions and definitions of good and bad quality of life, and how it can be improved for them, that valid models, and measurement instruments, of quality of life can be developed. More thorough research is also required if the complexity of the concept of quality of life can be better understood in terms of the variables that make up life quality, the variables which influence this, and the variables that act as mediators to the effects of adverse effects and circumstances. These might include level of adaptation and cognitive factors built up over time, including the way in which people make social comparisons of themselves with others and which then influences their expectations for themselves (e.g., after they have evaluated the gap between that which is desired and that which is achieved).

A study of perceptions of quality of life, based on 331 Canadian adults aged 58 and over, by Fry (2000) aimed to elicit the views and preferences of a sample of older people themselves. Contrary to negative stereotypes of older people as frail, vulnerable, and with deteriorating well-being, she showed that most respondents demanded autonomy, control, and independence in decision making. The author cited Scanlon's (1993) "substantive good theory" of quality of life to support this approach: assessment should involve a substantive judgment about 
what makes life better for individuals, and assessment should allow for expression of individual differences. This study, like that of Fry (2000), looks at how older people themselves define what constitutes quality of life and what they believe would improve it for them and others of the same age.

\section{AIMS OF THE STUDY}

The aim of the study was to define the constituents of quality of life in older age. The research questions were: 1) How do people aged 65 and over define and prioritize quality of life- both good and bad? 2) How do they feel it can be improved?

\section{METHOD}

The data presented here are derived from a national interview survey of quality of life in older age in Britain (the ESRC/MRC Quality of Life Survey). Age 65 and over was taken to denote older age. The vehicle for the survey was the Office for National Statistics Omnibus Survey in Great Britain. This is a face-to-face interview survey, in respondents' homes, conducted with approximately 1,900 adults, aged 16 or older, in private households in Britain (conducted monthly or every two months). Individual researchers can buy modules on the Omnibus Survey or use the Omnibus Survey to sift eligible respondents for further interview. The Omnibus Survey provides a relatively large, national, random sample which comparisons with population estimates from the 1991 Census and the annual ONS General Household Survey suggest is representative of the British population (note the survey coverage is of Britain south of the Caledonian Canal, excluding the sparsely populated Scottish highlands and islands).

\section{The Sampling Frame}

The sampling frame used was the British postcode address file of "small users." This file includes all private household addresses. A new sample of 100 postal sectors is selected for each Omnibus Survey. They were stratified by region, the proportion of households renting from local authorities, and the proportion in which the head of household is in socioeconomic group 1-5 or 13 (i.e., a professional, employer, or manager). The 100 postal sectors were selected with probability proportional to size. Within each sector 30 addresses were selected randomly with a target sample size per survey of about 2000 adults aged 16 and older (one per sampled household with the use of a random numbers table). Proxy interviews were not undertaken. Because only one household member is interviewed, people in households containing few adults had a better chance of selection than those in households with many. A weighting factor was applied to correct for this unequal probability. 
The Quality of Life Survey aimed to identify all respondents aged 65+ to the ONS Omnibus Survey for inclusion in the survey. Respondents from four Omnibus surveys, conducted at quarterly intervals over 12 months were used. All respondents aged 65 and older, who were interviewed for the Omnibus Survey (in April, September, November, 2000; January 2001 surveys) were asked if they would be willing to be re-interviewed by ONS interviewers on quality of life. Those who consented to participate further were re-interviewed two months later in their own homes.

\section{The Quality of Life Questionnaire}

The Quality of Life Questionnaire included structured questions and scales, along with open-ended questions, to elicit descriptions of respondents' quality of life, both good and bad, their priorities, and how quality of life can be improved for themselves and also for other people their age. This article presents analyses of the responses to the open-ended questions on quality of life.

\section{Procedures for Developing the Measures}

The content of the questionnaire on quality of life was informed by data from three focus groups with people aged 65, organized by the ONS Question Testing Unit. Focus groups have the advantage of making use of group dynamics to stimulate discussion, gain insights, and generate ideas. They can be used to examine people's ideas and beliefs, and the reasonings and understandings behind them. It is a useful technique for exploring a complex concept such as quality of life and its measurement. The advisory committee for the study also included three representatives of older people who provided additional feedback. The questionnaire was also built on previously used open-ended questions on the important things in life (Bowling, 1995a). ONS Omnibus staff also advised on question wording and scales.

The structured questions and scales were derived from a literature review of quality of life, and included psychological self-construct: perceptions self-efficacy (mastery and control over life) (Schwarzer, 1993), perceived risks of negative life events (Sutton, 1998), optimism-pessimism bias (Scheier \& Carver, 1985), health values (Lau, Hartman, \& Ware, 1986), physical functional status (Bond \& Carstairs, 1982; Martin, Meltzer, \& Elliot, 1988; Townsend, 1979), the SF-36 item on health perceptions (Ware, Snow, Kosinski, \& Gandek, 1993), psychological morbidity (GHQ-12) (Goldberg \& Williams, 1988), personal social capital (perceived social network structure and support) (Sherbourne \& Stewart, 1991), number and type of social contacts and social activities, perceived loneliness, and external social capital (perceived quality of local facilities, safety, problems within the area and neighborliness of area) (Cooper, Arber, Fee, \& Ginn, 1999), additional items on social networks, social comparisons, and expectations, and standard Omnibus Survey socio-demographic and socio-economic characteristics 
and classifications, as well as population density and type of area classifications (Acorn classifications of affluence). The analyses have been reported in detail in a separate article (Bowling, Bannister, Sutton, Evans, \& Windsor, 2002).

The open-ended questions used were:

- Thinking about your life as a whole, what is it that makes your life good - that is, the things that give your life quality? You may mention as many things as you like.

- What is it that makes your life bad - that is the things that reduce the quality in your life? You may mention as many things as you like.

- Thinking about all these good and bad things you have just mentioned which one is the most important to you?

- What single thing would improve the quality of your life?

- What single thing, in your opinion, would improve the overall quality of life for people of your age?

\section{Global Quality of Life Rating}

In this section, respondents were also asked to rate the quality of their lives overall on a 7-point Likert category scale as "So good it could not be better," "Very good," "Good," "Alright," "Bad," "Very bad," or "So bad it could not be worse." This was based on the global rating used by Hickey, O'Boyle, McGee, and Joyce (1999) in their Schedule for the Evaluation of Individual Quality of Life.

\section{Categorization of Themes}

After completion of the interviews, verbatim transcripts were produced and circulated among the research team. The coding frames for the open-ended questions were developed at meetings of the research team where emergent themes and any redundancies which arose requiring merging of categories were discussed. A list of themes was generated from these discussions, and tested on further batches over a six week period (by AF, LMD, AB). Regular reviews were held in order to assess any new themes which emerged. The manual categorization of themes from the open-ended responses on quality of life was carried out by $\mathrm{AF}$ and $\mathrm{LMD}$, with checks by $\mathrm{AB}$ who read each transcript. They were categorized manually into broad themes (labelled as "root themes" and then into cross-linked detailed sub-themes which were labelled as "branch themes") (see Figure 1 for the broad theme "roots" and the summaries of the detailed sub-theme "branches"). Responses usually contained more than one type of theme and were therefore multi-coded. They were analyzed in two ways, once by counting number of respondents per main theme (main theme mentioned a maximum of once per respondent) and then by analyzing the total number of main themes mentioned by all respondents using the multiple response 


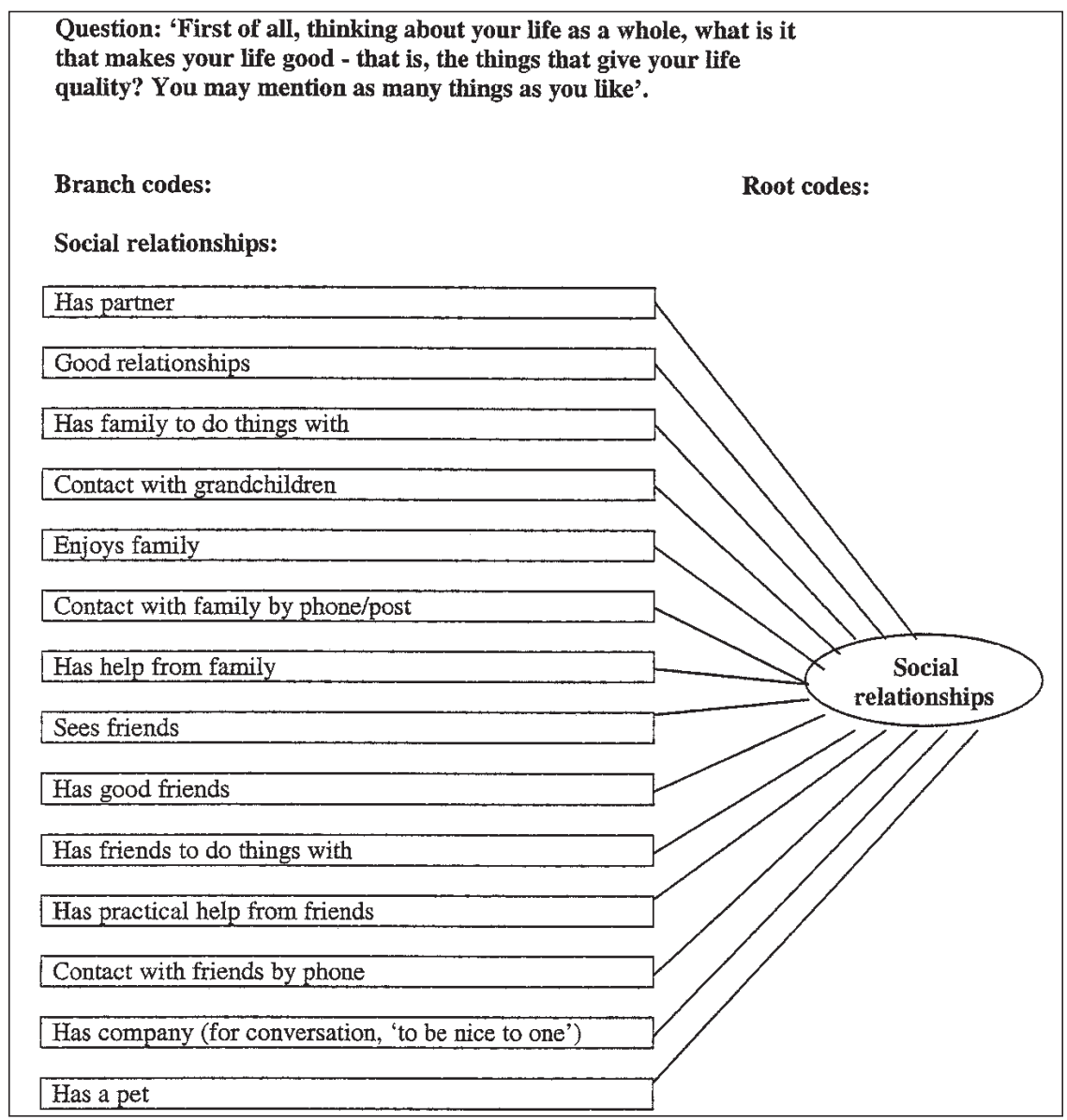

Figure 1. Multidimensional model of good quality of life (Part 1 of 7 ).

("MULT-RESPONSE") facility in SPSS10. All sub-themes were analyzed as multiple responses.

This categorization of open-ended survey responses represents a form of content analysis and should not be confused with qualitative research which employs smaller samples in order to provide deeper insights into people's lives, in order to understand their reasoning and perspectives (though this approach forms part of a separate ongoing sub-study of quality of life by the authors). The analysis of open-ended responses is more limited, but nonetheless insightful in terms of providing the researcher with the wide range of understandings and interpretations of concepts that people use. 


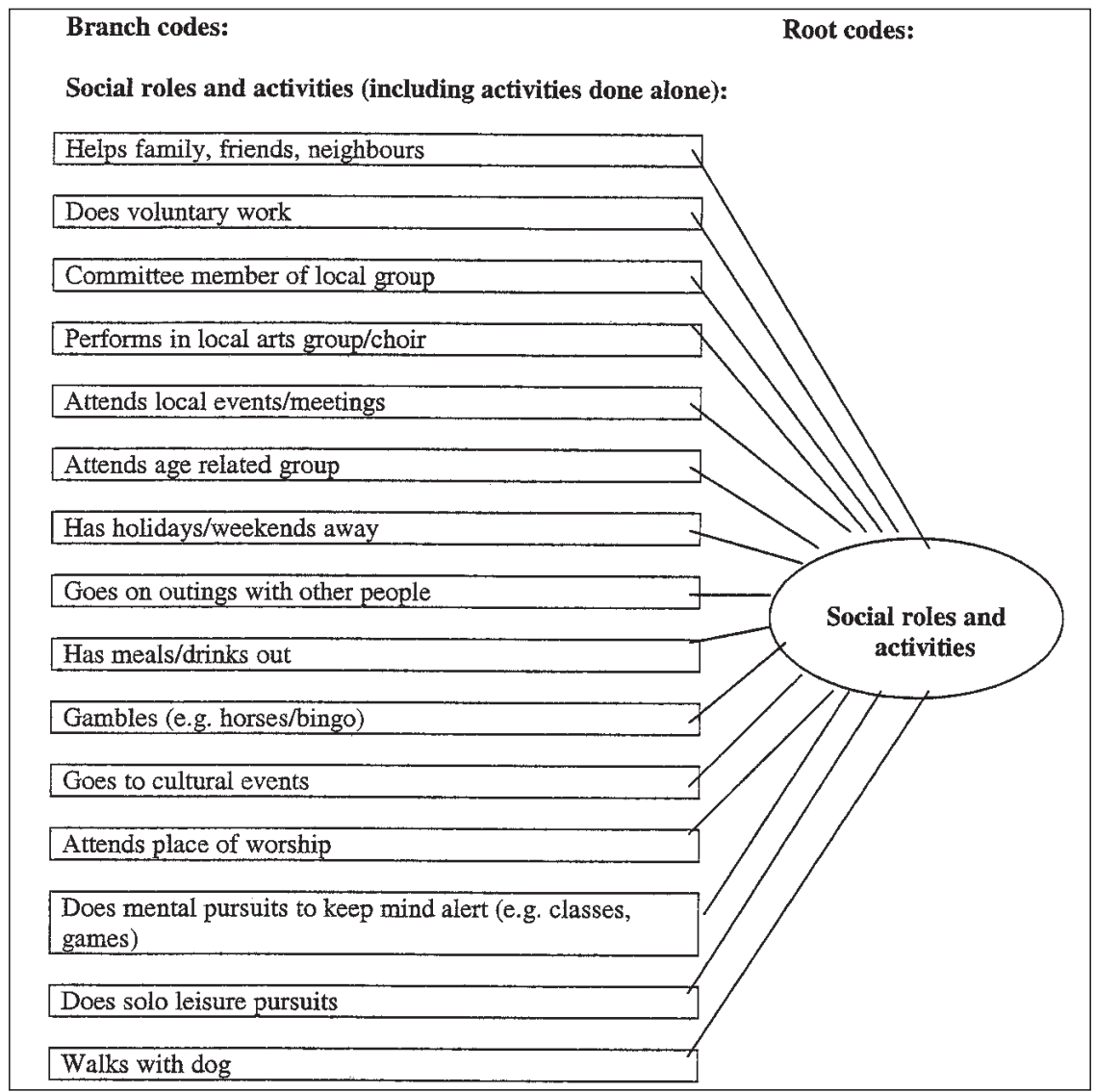

Figure 1. (Cont'd.)

(Part 2 of 7 )

Each open-ended theme that was coded (in relation to good, bad, and most important areas, and areas that could be improved for self and others) was analyzed by between one and three of the respondents' characteristics and relevant circumstances. These are presented here where statistical significance was achieved at least at the level of $p<0.01$, in order to minimize drawing attention to associations which could have occurred by chance, given that 95 separate tests were conducted (all results presented achieved significance at the $p<0.001$ level, except in two cases which achieved significance at the at $p<0.04$ and $p<0.01$ levels; the former is also reported here as the result was consistent with other data presented). 


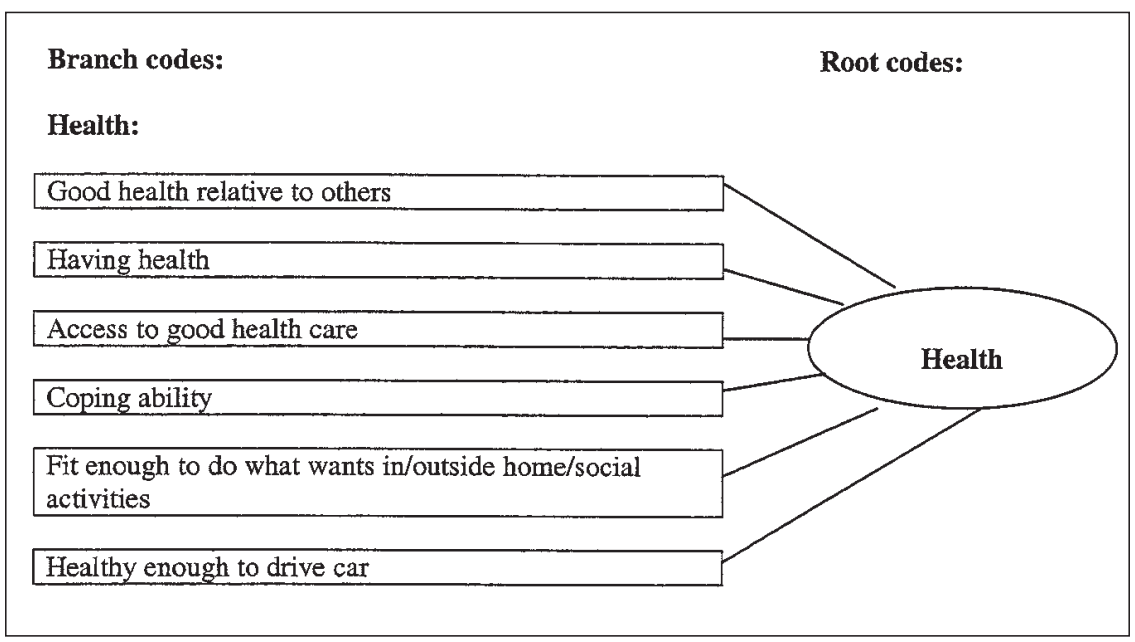

Figure 1. (Cont'd.)

(Part 3 of 7 )

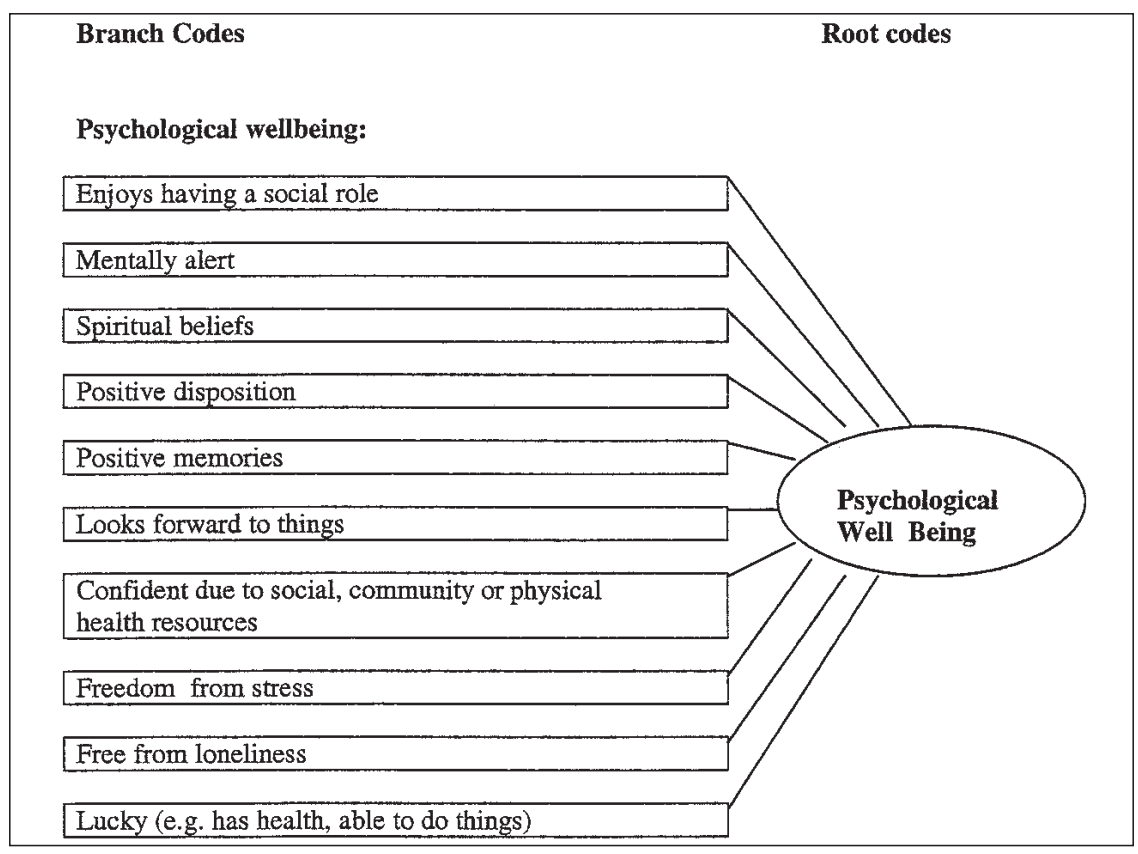

Figure 1. (Cont'd.)

(Part 4 of 7 ) 


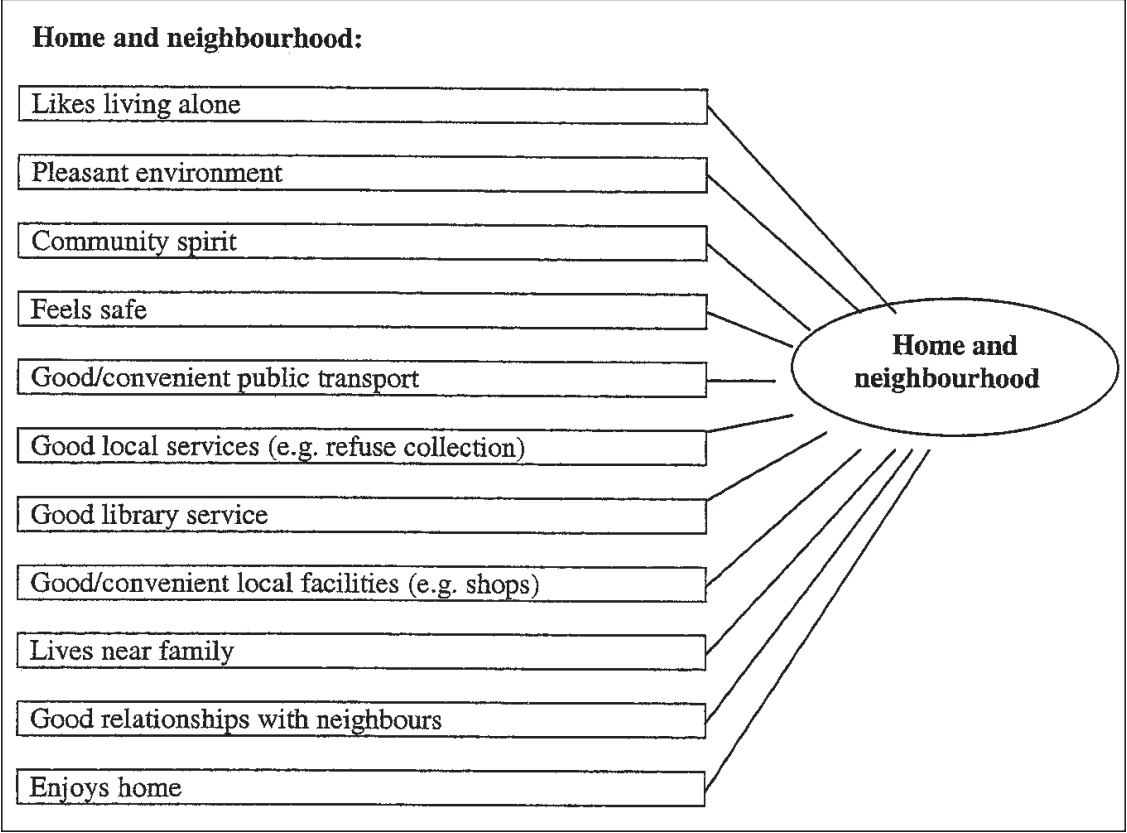

Figure 1. (Cont'd.)

(Part 5 of 7 )

\section{RESULTS}

Response rates - The overall (combined) response rate for the four main Omnibus Surveys (April, June, September, November, 2000), which acted as a sift for the QoL survey sample of people aged 65 and older, was 62 percent $(6,711)$ adults (with a range over the four surveys of 57 percent to 65 percent). Of these adult respondents, 1,598 were aged 65 and older, which is close to the number expected from mid-population estimates derived from the 1991 census.

The subsequent Quality of Life interviews with Omnibus Survey sample respondents aged 65+ took place in July, September, November-December, 2000 and February 2001. The overall (combined) response rate for these four Quality of Life Surveys was 77 percent (999) out of those respondents to the Omnibus Survey who consented to be re-interviewed for the QoL Survey (the range over the four surveys was 69 percent to 83 percent), or 63 percent of the 1,598 people aged 65 and older interviewed for the Omnibus Survey-both consenters and non-consenters to further interview). Both response rates are listed below. 


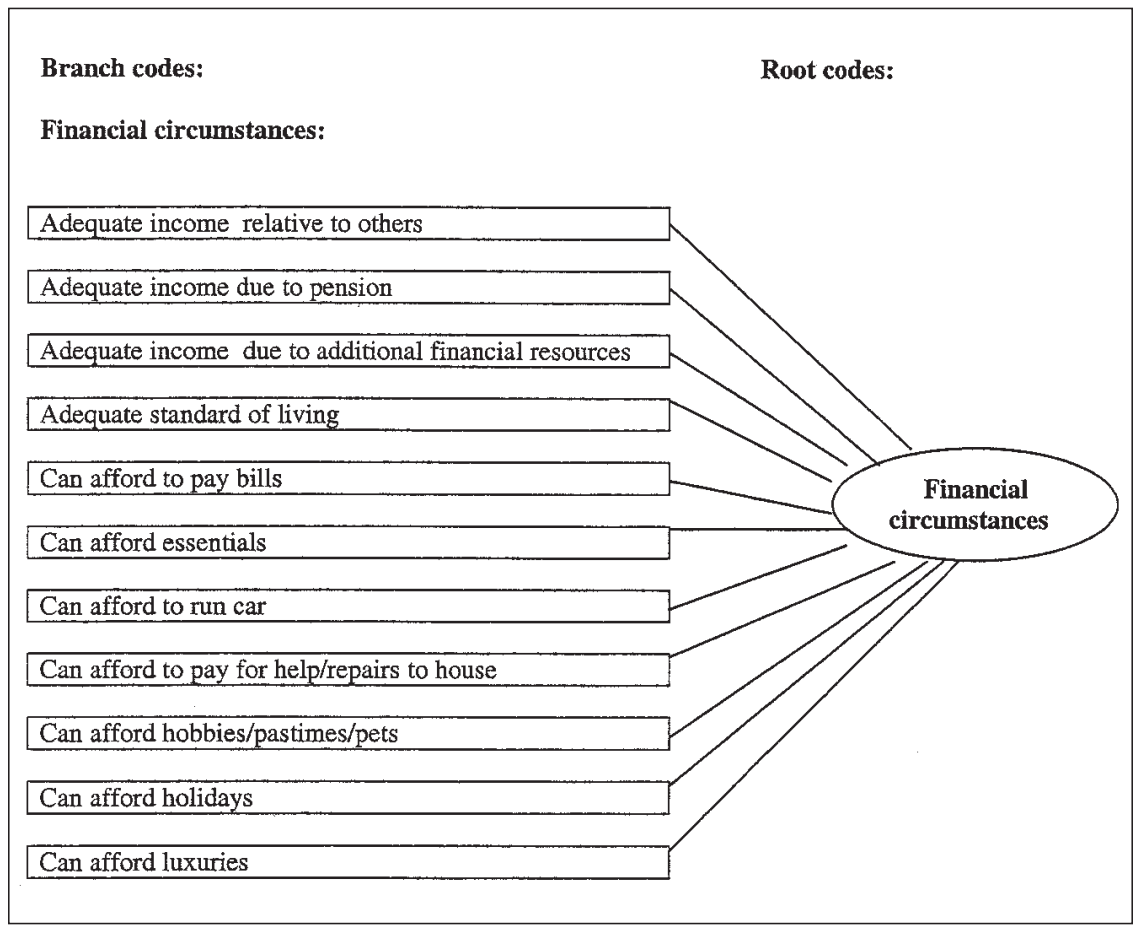

Figure 1. (Cont'd.)

(Part 6 of 7 )

Response Rates to Omnibus Survey and Quality of Life Survey

\section{Omnibus survey response:}

Selected addresses

(N) $\%$

Ineligible addresses

$12,000 \quad 100$

Eligible addresses

1,089

10,909

Refusals

$3,034 \quad 28$

Non-contacts

$1,164 \quad 11$

Interviews achieved

$6,711 \quad 62$

\section{Omnibus survey interviews}




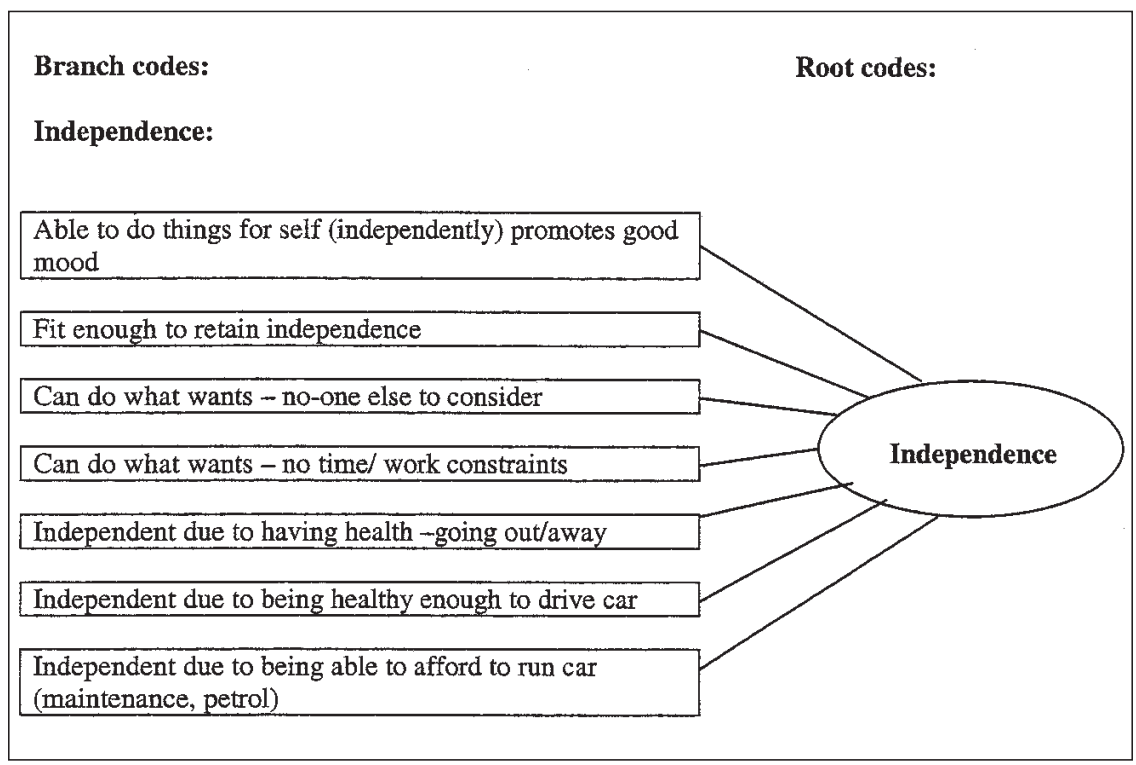

Figure 1. (Cont'd.)

(Part 7 of 7 )

\section{QoL survey response:}

Selected individuals

Ineligible individuals

$1,323 \quad 100$

Eligible individuals

$24 \quad 2$

Refusals on re-contact

1,299

Non-contacts during QoL fieldwork stage

$243 \quad 19$

Interviews achieved*

$57 \quad 4$

99977 (or 63 percent

of the 1,598

Omnibus Survey

respondents

aged 65 and older

(*This includes seven partial interviews)

Characteristics of respondents-Table 1 shows the characteristics of respondents. This shows that the sample was evenly divided between men and women, and that just under two-thirds were aged 65-74; most were married or widowed, a third lived alone, and most were white, as would be expected in a national sample of people aged 65 and older. Almost half had left school at age 14 or below and almost two-thirds had no formal qualifications, again as expected in this age 
group. Sixty-nine percent also reported an annual income of less than $£ 9,360$ $(\$ 15,161)$, and for most of these it was considerably less. However, about two-thirds had access to a car or van in the household, and all but 24 percent owned their home outright or on a mortgage.

\section{Global Quality of Life Rating}

There were no statistically significant differences with overall quality of life rating and age or gender. The majority of respondents (77 percent, 765) rated their quality of life as "Very good" or "Good." Five percent (53) rated it as "So good it could not be better," 15 percent (150) rated it as "Alright." Three percent (30) rated it as "Bad" or "Very bad" or as "So bad it could not be worse."

\section{Open-Ended Questions}

Defining good and bad quality of life - Figure 1 shows the broad main themes (or "root codes"), and the more detailed sub-categories of the themes (or "branch codes") which were identified by respondents for definitions of "good" quality of life. Most "bad" quality of life areas were reversals of these good themes (except where indicated in the text later). Figure 1 represents the views of respondents and therefore does not indicate the direction of any potential associations, or the relative importance of these views.

Respondents were asked: "First of all, thinking about your life as a whole, what is it that makes your life good - that is, the things that give your life quality? You may mention as many things as you like." Figure 1, then, displays the good areas mentioned. Respondents were asked next: "And what is it that makes your life bad - these are the things that reduce the quality of your life? You may mention as many things as you like." Most replies to this question on "bad" areas were simply the reverse of the "good areas."

Table 2 shows the broad domains mentioned by people — good, bad, and both mentioned. Several sub-themes within each main theme were mentioned and each of these was coded. For clarity of presentation, Table 2 shows the number of respondents who mentioned each main theme once only.

Table 2 shows that respondents emphasized several constituents of a "good" quality of life, including the importance of having good social relationships and contacts, having social roles and activities (including those enjoyed alone), having their health, having a positive psychological outlook and well-being, living in a good home and neighborhood, adequate finances, and retaining independence. The "bad" areas which took quality away from life which were mentioned often reflected losses in life: deteriorating health, bad features of home and neighborhood, reduced finances, poor psychological well-being, wider society/politics, and loss, or lack, of good social relationships. There were no significant differences with age or gender and the type of the themes which were mentioned as either "good" or "bad." 
284 / BOWLING ET AL.

Table 1. Characteristics of Respondents Aged $65+$ to ONS Omnibus QoL Survey

\begin{tabular}{|c|c|c|}
\hline & Percent & $(N)$ \\
\hline \multicolumn{3}{|l|}{ Sex: } \\
\hline Male & 52 & $(519)$ \\
\hline Female & 48 & $(480)$ \\
\hline Total & 100 & (999) \\
\hline \multicolumn{3}{|l|}{ Age: } \\
\hline $65-74$ & 62 & $(624)$ \\
\hline $75+$ & 38 & (375) \\
\hline Total & 100 & (999) \\
\hline \multicolumn{3}{|l|}{ Marital status: } \\
\hline Single, never married & 5 & (55) \\
\hline Married/cohabiting & 62 & $(619)$ \\
\hline Married, separated from spouse & 1 & (10) \\
\hline Divorced & 5 & (45) \\
\hline Widowed & 27 & $(271)$ \\
\hline Total & 100 & (999) \\
\hline \multicolumn{3}{|l|}{ Ethnic status: } \\
\hline White & 98 & (983) \\
\hline Black Caribbean & 1 & (7) \\
\hline Other & 1 & (8) \\
\hline Total & 100 & $(998)$ \\
\hline \multicolumn{3}{|l|}{ Age left full-time education: } \\
\hline Up to $14^{a}$ & 48 & $(491)$ \\
\hline $15-18$ & 41 & (406) \\
\hline $19-25$ & 8 & $(76)$ \\
\hline Over 25 & 3 & (27) \\
\hline Total & 100 & (999) \\
\hline \multicolumn{3}{|l|}{ Highest education qualification: } \\
\hline Degree of higher degree & 6 & (64) \\
\hline Higher educational qualification below degree & 6 & (63) \\
\hline A levels or higher & 4 & (38) \\
\hline ONC/BTEC & 2 & (20) \\
\hline O level or GSCE equivalent & 8 & (78) \\
\hline GCSE grade D-E or GCSE grade 2-5 & 1 & (14) \\
\hline Other & 9 & (84) \\
\hline No formal qualifications & 64 & $(637)$ \\
\hline Total & 100 & (999) \\
\hline
\end{tabular}


Table 1. (Cont'd.)

\begin{tabular}{|c|c|c|}
\hline & Percent & $(N)$ \\
\hline \multicolumn{3}{|c|}{ Gross annual income before tax: } \\
\hline Less than $£ 4,160$ & 23 & $(218)$ \\
\hline$£ 4,160<£ 6,240$ & 24 & (223) \\
\hline$£ 6,240<£ 9,360$ & 22 & (212) \\
\hline$£ 9,360<£ 17,680$ & 21 & (202) \\
\hline$£ 17,680$ or more & 10 & (97) \\
\hline Total & 100 & (952) \\
\hline \multicolumn{3}{|l|}{ In paid work in last 7 days: } \\
\hline Yes & 5 & $(49)$ \\
\hline No & 95 & (950) \\
\hline Total & 100 & (952) \\
\hline \multicolumn{3}{|c|}{$\begin{array}{l}\text { Socio-economic group } \\
\text { (for those who ever had paid job): }\end{array}$} \\
\hline Professional & 5 & $(45)$ \\
\hline Employers and managers & 19 & $(175)$ \\
\hline Intermediate non-manual & 14 & (128) \\
\hline Junior non-manual & 15 & (146) \\
\hline Skilled manual & 23 & (223) \\
\hline Semi-skilled manual & 18 & (172) \\
\hline Unskilled & 6 & $(59)$ \\
\hline Total & 100 & (949) \\
\hline \multicolumn{3}{|l|}{ Social class: } \\
\hline I Professional & 5 & $(48)$ \\
\hline II Intermediate & 28 & (265) \\
\hline IIInm Skilled non manual & 20 & (189) \\
\hline IIIm Skilled manual & 24 & (229) \\
\hline IV Partly skilled & 16 & (156) \\
\hline V Unskilled & 7 & $(62)$ \\
\hline VI Armed forces & - & (2) \\
\hline Total & 100 & (951) \\
\hline \multicolumn{3}{|l|}{ Car/van available to household: } \\
\hline Yes & 67 & (665) \\
\hline No & 33 & (334) \\
\hline Total & 100 & (999) \\
\hline
\end{tabular}


Table 1. (Cont'd.)

\begin{tabular}{lrr}
\hline & Percent & $(N)$ \\
\hline Region of residence & & \\
North & 25 & $(251)$ \\
Midlands and East Anglia & 28 & $(280)$ \\
London & 7 & $(72)$ \\
South East & 14 & $(140)$ \\
South West & 13 & $(127)$ \\
Wales & 5 & $(53)$ \\
Scotland & 8 & $(77)$ \\
Total & 100 & $(999)$ \\
Number of adults in household: & & \\
1 & & \\
2 & 33 & $(330)$ \\
3 & 60 & $(590)$ \\
Total & 7 & $(68)$ \\
& 100 & $(988)$ \\
Type of household: & & \\
One person only & 33 & $(330)$ \\
Married/cohabiting-no dependent children & 59 & $(592)$ \\
Lone parent-no dependent children & 1 & $(8)$ \\
Other & 7 & $(68)$ \\
Total & 100 & $(999)$ \\
Respondent's own housing tenure: & & \\
Owns home outright & & \\
Owns home on mortgage/loan & 69 & $(692)$ \\
Rents & 7 & $(68)$ \\
Lives here rent free & 24 & $(238)$ \\
Total & - & $(-)$ \\
\hline & 100 & $(998)$ \\
\hline Includ & &
\end{tabular}

${ }^{a}$ Includes five who did not receive any education.

Respondents commented on the subjectivity and multifaceted nature of quality of life, as well as the interdependent nature of its component parts. For example, having independence and social activities are often dependent on retaining good health and an adequate financial situation, as well as access to transport. Some of the main emergent themes are explored in more detail below.

Social relationships-Social relationships was the most common theme which was identified by respondents ( 81 percent) as giving life quality ("good" QoL). People who had experienced a married relationship were the most likely to say 


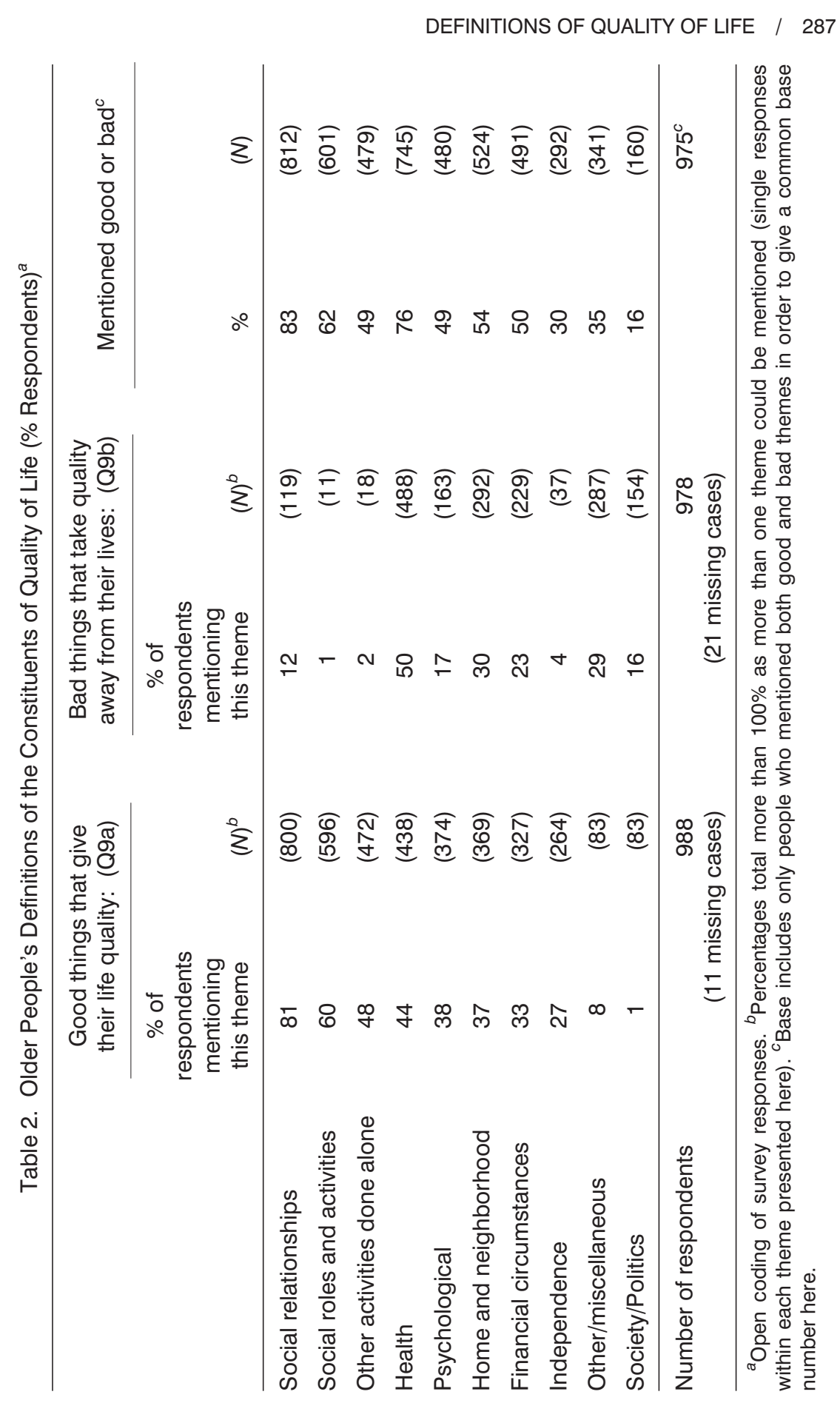


this: that is, those who were widowed (89 percent, 244), married (78 percent, 474) or divorced/separated (73 percent, 38 ) in comparison with single people and those who were cohabiting (66 percent, 37 and 67 percent, 6 respectively) said this) $\left(\chi^{2}(4)=23.806, p=<.001\right)$. Reported loneliness did not show any consistent pattern with mentioning social relationships as making up a good QoL.

Social relationships with family, friends, and neighbors were important to people for companionship, people to do things with (going out, going on holidays), to help practically, to care for ("to be nice to me"), prevent loneliness, and promote psychological well-being. Respondents referred to the importance of having a family generally, and having a good, close, supportive, loving relationship with their family and/or having a good/compatible/loving/or familiar relationship with their partner. Respondents mentioned the importance of having someone for "companionship," to "take me out," "to make life bearable," to "know there is someone there willing to help me," or "look after me." Some respondents commented that this gave them confidence. The importance of living in a supportive and friendly neighborhood when health has deteriorated and when people feel vulnerable was also illustrated by several respondents. Some of their replies are shown below:

I have a good family, plenty of friends, and lots of interests. I have lots of friends that come to wait for me and will take me wherever I want to go- and good neighbors. The man next door takes me shopping and to the doctor's in his car, and his wife does take me shopping if needed. Next door but one the neighbor keeps me company in the evenings. (3040 1 0012)

Good neighbors - all friendly. Four doors down the man called me to give me broad beans. When I did not put my washing line up he came round to see if there was any problem or I needed help. The lady two doors down does my eye drops three times a week. There are always times I need a doctor, she rings for me. They are all very good to me. (10485)

Meaningful contact, face-to-face or by telephone, with sons and daughters was important to most respondents for enjoyment, help, and security. Respondents said they enjoyed doing things and going out with their families, as well as seeing them achieve things and progress. Contact with grandchildren (and being able to play and go out with them) was frequently mentioned. It was through their grandchildren that they felt able to play a reciprocal role, and to feel useful and valued, which was emphasized as important to them.

The quality of my life now is my family - my children and grandchildren. My life surrounds them. I go at weekends, they visit every week. Sometimes I have the younger grandchild staying overnight. . . . I can do things with the family. I'm there if they need me. I get them bits for their flat and make them more comfortable. I knit them big jumpers and just look out for them. (2002 4 0009) 
My grandchildren. Well I'm noted for activity. I can't keep still. The grandchildren love to come and go out with me. We like the cinemas, we like the parks, you name it. ... At least somebody thinks I'm useful. ... The youngest, who is nine, is dyslexic so that can be very awkward. They're too different. They rely on me more-my sons - for hospital appointments, and doctors' appointments, now I've got the time. (10321)

Without a reciprocal role, some were afraid of being seen to be a burden by their families, and also referred to their families' own time constraints in providing social contact and support.

Both my daughters' husbands and grandchildren are good to me, but I feel I can't just keep pestering them. I am a little bit independent. They have their lives to live. (10434)

Pets were mentioned by some as important alongside their families - for love (both directions), company, and for the pets' dependency.

My family - my son, my daughter-in-law, and my two grandchildren. ... Oh, and my little cat. I talk to her a lot, she's just like a little child. She doesn't like being left alone, I love her to bits. Now and again I give her a little kiss. (10141)

Having good friends, as distinct from neighbors and family, was also emphasized in relation to providing company (e.g., mixing, conversation, self-esteem), as opposed to providing practical help which was a role identified mainly for relatives and neighbors. One respondent said:

Friends isn't it? They take me out for days and we have a social evening once a week. There are six of us and we go round to one another's houses and we play cards. . . . We have these clubs for pensioners. I'm in two clubs and they come to fetch us in the buses. (3085 5 0012)

In relation to "bad" areas, 12 percent of respondents mentioned poor social relationships taking quality away from their lives. Respondents who were widowed were the group most likely to mention this (24 percent, 67), followed by those who were divorced/separated (14 percent, 7), single (11 percent, 6$)$, married (6 percent, 39) and none of those who were cohabiting said this $\left(\chi^{2}(4)=59.463\right.$, $p=.001)$. Respondents who reported feeling lonely "always," "often," or "sometimes" were more likely to mention relationships in terms of bad QoL (i.e., not having good relationships) (44 percent, 7; 37 percent, 18; 17 percent, 53 respectively) in comparison with far fewer (7 percent, 41) of those who said they never felt lonely) $\left(\chi^{2}(3)=66.626, p<.001\right)$.

For some, poor social relationships were due to difficulties maintaining contacts or good relationships with their families, either because of geographical distance, their families being "too busy" to visit them, or family feuds. Moving in with relatives was also mentioned as a source of strain. 
When we sometimes have words and rows in the family. The worry with my daughter-she's not good patient, she's got rheumatoid arthritis. . . . I do most of the housework. I worry a lot about what's going to happen to us when I get too infirm to do anything. I came here so as not to be on my own, but it's worrying when I came here to be looked after but I do the looking after. (3035 3 0012)

For others, poor relationships were due to difficulties looking after grandchildren.

I have a grandson with learning difficulties, we love him greatly. He comes regularly and we have him a lot because his parents are in business and his quality of life would be bad if we did not have him. At the end of the day I am very tired. He has lack of concentration so he is on a short fuse. . . . He does not concentrate on what we tell him to do. (10452)

An item which did not have a reverse positive match in Figure 1 was missing family/friends or a partner who had died for their familiarity or love, for doing practical tasks, and sharing responsibility and decision making. One recent widow commented that she had:

No hand to hold. . . . Socially I am a person non-gratia, being seen by other wives as a threat. . . I I am pulling myself up, all I want is mature company to help me. (4060 1 0102)

Social roles and activities-Participation in social, leisure, and educational activities and also in local community and voluntary activities was also reported to be important to life quality by 60 percent of respondents ("good"). This theme was rarely mentioned in relation to bad QoL (by 1 percent) (i.e., not having social roles and activities).

Respondents who had a high level of social activities (social activity score of 5-12 or 3-4 activities) were more likely to say this (69 percent, 225 and 62 percent, 208 respectively) than people with just one or two activities (50 percent, 132), or who had no social activities (43 percent, 29$)\left(\chi^{2}(3)=31.434, p<.001\right)$. Reported loneliness was not associated with mentioning this theme (good or bad), and the association with number of face-to-face contacts was inconsistent.

Respondents undertook a wide range of voluntary work for charities, and for local clubs and committees. Other social activities they reported included being engaged in helping friends, neighbors, or family (e.g., with child care, collecting shopping items), having holidays/weekends away, attending age-related clubs, performing in local arts group/choirs, going to theater/cinema/concerts/opera, going out for meals, drinks, going on outings/day trips, bingo, gambling on horses, evening and other educational classes, pub quizzes, bridge, going to church/place of worship, undertaking sports/physical activities (swimming, table tennis, cycling, snooker, bowls, dancing, keep fit), and going for walks including walking 
the dog. Respondents with dogs commented that walking the dog helped them to meet other people.

About half (48 percent) of the respondents mentioned their independent ("solo") activities and amusements - usually undertaken at home, alone - as giving their life quality. These included crafts (e. g., woodwork, sewing, knitting, restoring antiques), cooking and diet, listening to music/radio, watching TV/videos, reading, mental activities (crosswords, jigsaws, competitions), gardening/tending allotment, watching wildlife (e.g., birds, foxes, squirrels). Mention of independent activities was not associated with marital status or household composition or size. Many respondents referred to their social activities in the context of the importance of "keeping busy." As two said:

Well, I think being busy really. I'm keen on repairing things and do-ityourself. . . . I play snooker three or four times a week . . . and two evenings I have a couple of pints. (10633)

I never sit down, the days just fly by. I think that working voluntary at the hospital is a good eye opener, you get out . . . be thankful it is not me. (2049 1 0009)

Health-The importance of having and retaining good health for a "good" quality of life was mentioned by 44 percent of respondents. Respondents who did not report having a longstanding illness, disability, or infirmity were more likely than those who did report this to mention having their health as contributing to their good quality of life: 53 percent (202): 38 percent (236) respectively $\left(\chi^{2}(1)=20.863, p<.001\right)$. Similarly, those with no or slight difficulty with physical functioning and performing activities of daily living were more likely to mention their health as giving their lives quality (54 percent, 169 and 52 percent, 169 respectively), in comparison with 35 percent (46) of those with moderate difficulties, 24 percent (30) of those with great difficulties, and 21 percent (18) of those with severe difficulties $\left(\chi^{2}(4)=107.338, p<.001\right)$.

A few respondents made downward comparisons in relation to health, including to their parents' health in the past. They appeared to employ downward social comparisons to help them cope with their problems and maintain their morale or self-esteem.

Seeing other people who are not well makes me feel lucky that I still have good health. (10512)

For the majority, having good health was most central to retaining their independence and their perceptions of a good quality of life. In some cases, people prioritized their health because of their negative health events in the past. This is illustrated by the following respondent, who made downward comparisons with others, as well as herself in the past, because of her life threatening health condition. 
I have just had a pacemaker fitted, and therefore I have been given an extension of my life and therefore there must be a purpose for me, and I use every opportunity to speak to people. I am grateful for a good night's rest and that I can get up in the morning, hear the birds, see the flowers, and that I can see. My blessings are that I can do many things that other people cannot do. . . Many people cannot see, walk, or enjoy life, so my blessings are many. (2056 3 0009)

Others expressed relief that they were still alive or that they were still living in their own homes.

I am still here, I am still in my own home. . . . A friend comes in to wash me and I get help from others which means I can keep on living in my own home. I can get about in the house, and I read a bit and watch telly. It's nice here in the summer and I feed the birds. Well, I'm still breathingjust. Just as long as I can stay in my own home. (4046 2 0102)

Coping ability in relation to health was mentioned here in a positive sense. People with health problems, referred to making "the best of things," "being able to do things despite health problems," and the importance of being able to "keep going." Others prioritized their good health because it was essential to their continued enjoyment of life. Some emphasized the importance of being fit enough to do what they wanted (including general and social activities, going out as much as they want, doing hobbies, and looking after grandchildren), and being fit enough to continue driving was particularly valued.

Not having good health was emphasized by 50 percent of respondents in relation to "bad" quality of life. Respondents who reported having a longstanding illness, disability, or infirmity (61 percent, 377) were more likely to mention this theme than those who did not report a longstanding condition (29 percent, 111) to mention this theme $\left(\chi^{2}(1)=95.715, p<.001\right)$. Again, those who had severe or great difficulties with activities of daily living ( 81 percent, 69 and 71 percent, 89 respectively) were more likely to say their poor health took quality away from their lives than those with moderate (58 percent, 78), slight (46 percent, 148), or no difficulties (31 percent, 98) $\left(\chi^{2}(4)=107.338, p<.001\right)$.

Some of these respondents made comments concerning the lack of effective medical treatment for their condition. The negative effects of poor health on their lives were described in relation to not being fit enough to do what they wanted to, being unable to go out, and being unable to participate in specific social and leisure and other activities due to ill-health (e.g., sports, playing with grandchildren, walking, listening to radio, hobbies, playing with grandchildren, unable to continue with voluntary work); being unable to look after themselves or their home (e.g., bathing, housework, shopping, gardening); difficulty listening on the phone or to concerts or the radio (poor hearing). 
As the next examples illustrate, deteriorating health and consequent social handicaps were reported to have led to depression in some, and to fears for the future, especially when respondents lived alone or faced cumulative losses.

The end cannot come too soon I suppose. . . . I have loads of pain, I'm lonely, unhappy, and depressed. I would not care if my next angina attack was my last. I cry every day because I miss my husband so much. I no longer have any social life. Our friends seem to avoid me. I am a lone woman among couples. I have angina which prevents me from doing lots of things-I can no longer go to town shopping. (3002 2 0012)

I think when you live on your own and you're single you worry about what might happen to you if you get ill. If you have your health you can stay in your own house, it's free, but you do worry about what can happen when you get older. I have friends . . . but I have no family, and they (friends) are the same age, so you couldn't expect to get help there-all getting old together. (3018 10012 )

Respondents with worsening health disliked greatly their dependence on other people, although not all received the help they wanted.

First of all I've got impaired sight which is a great drawback and I suppose if I could see life would be a lot different. I'm not independent, that's been taken away from me. I like helping people but I don't like people helping me. I'm very independent and when that's taken away that makes life a misery. (10787)

Illness, health generally - the worry that you might not be able to do what you have been doing and what's going to happen next. . . . The things I can't do now. I used to play tennis until five years ago. . . . If my eyes go I shall lose my independence. I should hate to be dependent on somebody else. (10783)

Psychological outlook and well-being-Psychological outlook and well-being was mentioned by 38 percent of respondents in relation to "good" quality of life. While respondents who did not have any psychological morbidity (mainly anxiety/depression), measured using the General Health Questionnaire-12, were slightly less likely than those who scored as such cases to mention this: 31 percent (62): 39 percent $(308)\left(\chi^{2}(1)=4.164, p<.04\right)$, it is possible that this small difference could have occurred by chance given the large number of statistical tests carried out. Not necessarily consistent with this, those who mentioned poor psychological outlook/well-being as contributing to bad quality of life were more likely to score as cases of psychiatric morbidity (see later). There were no associations with having an optimistic or pessimistic disposition and mentioning this theme (good or bad).

These respondents emphasized the importance of their positive mental outlook in influencing quality of life in terms of having a positive disposition (happy/ satisfied/enthusiastic/content person), feeling they had a role in life, having good 
memories of the past (job, family, achievements). A few respondents also felt "lucky" in this context, suggesting a more fatalistic view of life.

The reasons for reporting poor emotional well-being, in relation to "bad" quality of life (by 17 percent), related mainly to declining health, loneliness, but also inability to do things after widow(er)hood, when taking on new (the deceased spouse's) tasks.

I get frustrated when I can't do things - when the Hoover goes off - practical things that is. I find the gardening frustrating - been ripped-off so many times by so-called gardeners, this annoys me. It's the things my husband always did and took care of. Well, he's no longer here to do those kinds of things. (10012)

Respondents who scored as having psychological morbidity with the General Health Questionnaire-12 were more likely than those who did not to report this: 25 percent (49): 14 percent $(113)\left(\chi^{2}(1)=12.358, p<.001\right)$.

Home and local neighborhood-The neighborliness of the area, leading to social integration, was a further theme of "good" quality of life, mentioned by 37 percent of respondents, including the pleasantness of the environment, and proximity to facilities. There was no association between mentioning this theme (as contributing to good or bad QoL) and Acorn classification of the area into type of neighborhood in which respondents lived in terms of affluence (as thriving, expanding, rising, settling, aspiring, striving), although mention of this theme as contributing to good QoL (but not bad) was associated with the population density of the area (numbers of people per hectare): 50 percent (89) of those who lived in the least dense neighborhoods mentioned home and neighborhood as part of a good QoL, in comparison with 29 percent (27) of those in the most dense areas (the trends were consistent and in the expected direction for those in the other five population density groups) $\left(\chi^{2}(6)=18.408, p<.01\right)$.

Living in a good neighborhood (feeling safe, secure, friendly area, community feeling), having good/friendly/helpful relationship with neighbors, having good local facilities (shops, markets, post-office) including a good local mobile/ library and good local council services (street lighting, refuse collection, police, repairs), having a pleasant landscape/surroundings was said to be important by respondents. Access to transport was said to be important for retaining independence.

If you can get on the bus and get about without disturbing anybody else I think that's a big thing really.... With the bus pass you can get on and off as you like without paying and saves my legs from walking. I'm happy that I can get about independently, and visit friends and that. (3056 2 0012)

Type of neighborhood was mentioned by 30 percent as adversely affecting their own quality of life ("bad"). It was seen as inhibiting social integration and social participation, and creating feelings of insecurity. These respondents 
did not feel that their area was safe or friendly, or said that it lacked a community spirit. Some of these reported perceived danger from local vandals, groups of youth or gangs, damage to property, burglars, and personal attack. Mention of home and neighborhood as contributing to bad (but not good) QoL was associated with respondents' ratings of their neighborhood as "very poor" in terms of local facilities for people aged 65 and over, rubbish collection, health services, transport, shops, and somewhere nice to go for a walk: 44 percent (56) of these respondents rated their neighborhood as "very poor," in comparison with 29 percent (114) and 25 percent (86) of those with middle area rating scores and 27 percent (37) of those who rated their neighborhoods as "very good" $\left(\chi^{2}(3)=\right.$ $16.276, p<.001)$.

Fear of crime and personal assault restricted some respondents' social activities and many said they would not travel at night.

Fear of crime is the first thing ... we would like to go out in the evening but are frightened to do it. ... We would like to but would not travel on the metro at night. (2001 10009)

Fears for the future and losing independence were sometimes heightened when people lived in areas with poor social resources and public services. Lack of easy access to reliable, cheap, and convenient public transport was mentioned as inhibiting social contacts and activities, and also gave emphasis to older people's perceived need to continue to drive.

Public transport is not good so I worry about getting around as I get older, especially as our friends are scattered-whilst we can drive there is no problem. (2065 30009$)$

Transport — the buses are not made for older people ... the steps to the ground are very steep. . . . It is hard for people to get off easily. (3057 1 0012)

Problems mentioned also included difficulties with neighbors (e.g., noisy neighbors, nuisance from children), poor local facilities (e.g., shops), poor local services (e.g., police, repairs, street lights, refuse collection, social work). The reverse negative item to the positive "enjoys home" in Figure 1 was "stressed by home" due to repairs that were needed and household chores that respondents found difficult. These data suggest that the neglect of home and neighborhood issues (or wider social capital) in current measurement scales needs redressing.

Financial circumstances-Having no financial worries about bills or debts, and having enough money for essentials, or being able to afford to run/maintain car/pay for petrol, was mentioned by 33 percent of respondents as giving quality to life ("good"). A few respondents referred to their income as adequate or favorable relative to others who were perceived to be worse off, with their parents or themselves in the past when worse off, representing downward health and wealth comparisons (there were no upward comparisons). 
Respondents who received the highest incomes (mainly in the form of retirement pensions) were the most likely to mention finances as contributing to their good quality of life: 54 percent $(52)$ of those with $£ 17680+(\$ 28,638)$ per annum said this, in comparison with 45 percent (91) of those with $£ 9360<£ 17680$ $(\$ 15,161<\$ 28,638), 26$ percent $(113)$ of those with $£ 4160<£ 9360(\$ 6,738<$ $\$ 15,161)$, and 25 percent $(54)$ of those with less than $£ 4160(\$ 6,738)\left(\chi^{2}(3)=\right.$ $49.603, p<.001)$. The responses of those in the lower income groups reflected low expectations and feelings that their income was adequate if they could "get by" and "pay off debts." Those in the higher income groups emphasized enjoyment and the importance of sufficient funds for continued participation in society - to enable them to do what they wanted, especially for pastimes and going away (generally called "luxuries").

Having sufficient income to do what I want. . . Having enough moneywithout being rich—makes me privileged compared with my parents. (10552)

Not having enough money was mentioned as a "bad" area of quality of life by 23 percent, particularly when savings were being depleted over time so few surplus funds were available to pay for household repairs or activities for enjoyment. Mention of finances as bad, however, was not associated with level of income, although an inadequate standard of living (cannot afford basics/ essentials, worries about bills) was often reported. Several said that their state pension was inadequate to meet their basic needs, that they could not afford luxuries such as outings or holidays, or that they could not afford to pay for help/house repairs.

The quality of life has deteriorated financially year by year from pensions. The annual increases not nearly enough. .. . The increases in fuel have caused financial problems. I have had to let my allotment go as I cannot afford to do anything. I am prevented travelling as much as I used to or would like. I am missing out three journeys to my caravan in the six month season. (10074)

. . more pension would help me to be able to enjoy myself more. I have to keep using my nest egg to have the jobs around the house done, and I have no way of building my nest egg up. Finance is the top thing really. (10233)

Independence-Having and retaining independence was mentioned as an essential feature of a good quality of life by 27 percent respondents, particularly being able to do things for oneself (including looking after home and garden), and 4 percent said loss of their independence (e.g., through declining physical mobility or inability to continue driving) made their quality of life bad.

While difficulty with performing activities of daily living was not associated with mentioning having independence (as good QoL), respondents who had severe or great difficulties with activities with daily living 11 percent (9) and 7 percent (9) were slightly more likely than those with moderate, slight, or no difficulties 
2 percent (3), 3 percent (8), and 3 percent (9) respectively to mention loss of their independence as taking the quality of their life away (bad QoL) $\left(\chi^{2}(4)=\right.$ $17.620, p<.001)$. There were no associations with mentioning independence (good or bad) and measures of self-mastery (e.g., amount of perceived control over the important things in life).

Several people said they valued their independence emphasizing that they were still fit enough to retain this. As one respondent stated, independence and the freedom to do what one wants depends on both health and financial resources.

Having my health and having a reasonable standard of living. Well they both give you the freedom to do what you want. You are not dependent on anyone (10041)

A common theme among respondents was that their independence was due to being able to continue driving, and being able to afford to run a car and pay for gas.

The car-it makes my quality of life. It allows me to travel to our caravan, out to get to the seaside. ... I am unable to walk far due to breathing problems and the car gives me independence to get about. (10074)

Flexibility and lack of time constraints interfering with independence, in relation to pursuit of leisure activities in retirement, or simply to do what one wanted (e.g., holidays, pastimes, getting up in the morning), were also valued.

If I decide I'm going to spend all day in bed and have bacon and eggs at 2 a.m., and go on holiday, or have a new suit, I can do them. Freedom for material things. . . . Freedom from pressure. (10581)

The freedom to do things when we want to . . instead of, when you're working, the things you have to do. . . . Last week we nipped off for two days to the Lake District, we didn't have to organise time-off from work. (10011)

Other areas - Issues relating to wider society and politics were mentioned as bad areas of quality of life (by 16 percent), rather than as good areas (1 percent). Particular reference was made to government policies which affected older people negatively (e.g., inadequate levels of state funded pensions, inadequate policies to combat crime), to negative world news which respondents said affected their mood adversely, pollution and environmental problems and policies, traffic and car parking issues, local library closures, general concern about poor standards of behavior in society, disrespectful or ageist attitudes and social values. Other "bad" areas of quality of life (mentioned by 29 percent) included reference to the poor British weather (cold, rain), and pressure to buy things by door-to-door salesmen.

Single most important aspect of quality of life - Respondents were asked which of the areas of quality of life they had mentioned was the single most important area to them. The two most frequently mentioned important areas were having good social relationships (e.g., having a good family/marriage/friends and 
neighbors, and pets) (mentioned by 37 percent) and having good health (37 percent).

People who were widowed or divorced/separated were the groups most likely to say social relationships were the most important (45 percent, 122; 42 percent, 22 respectively), in comparison with those who were married (35 percent, 211), cohabiting (30 percent, 3$)$, or single (13 percent, 7) $\left(\chi^{2}(4)=23.317, p<.001\right)$. Some people included their pets here.

The most important to me are my family and my dog-I don't know which one I would put first, as the dog is family. (102602)

Health was frequently said to be essential for the other aspects of life. As two people said:

Good health is needed to be able to carry on with the other activities I do. (105702)

You can't buy health, health must be the main source of satisfaction and happiness. (102703)

There were no significant associations with health and physical functioning and the people who mentioned, or did not mention, this theme.

Other areas prioritized, but by far fewer people $(<7$ percent in each category) included maintaining independence — being able to do things for themselves and continue with their social activities, having a good home and living in a good neighborhood, having a positive outlook (psychological well-being), having enough money, having social roles and activities, including solo activities (e.g., knitting, reading), society/politics (e.g., government policy on pensions or other areas which affected people's well-being).

Improving quality of life for themselves-Respondents were then asked what single thing would improve the quality of their lives. The most common responses were having better health and physical mobility (some also mentioned the need for better health care) (34 percent), having more money/a bigger pension (30 percent), followed having better social relationships with family members or friends/neighbors (although this was by fewer, 9 percent).

Respondents who reported having a longstanding illness were more likely than those who did not report this to mention having good health as the single area which would most improve their quality of life: 44 percent (274): 17 percent (66) $\left(\chi^{2}(1)=76.836, p<.001\right)$.

Again, those with severe or great difficulties with activities of daily living were more likely to mention having their health as the single area that would give quality to their lives (59 percent, 50 and 54 percent, 67) than those with moderate (39 percent, 15), slight (32 percent, 103), or no difficulties (21 percent, 65) $\left(\chi^{2}(4)=72.063, p<.001\right)$. 
There was also a significant association between reported loneliness and mentioning social relationships as the single thing that would improve their quality of life: 37 percent (6) of those who said they "always" felt lonely, 27 percent (13) of those who said they "often" felt lonely mentioned social relationships in this context, in comparison with fewer of those who said they "sometimes" felt lonely (11 percent, 34$)$ and those who said they "never" felt lonely (5 percent, 31$)$ $\left(\chi^{2}(3)=49.310, p<.001\right)$.

I'd like a friend, someone I could trust. (101401)

Living with someone to avoid loneliness. (103901)

My family living closer. (106806)

Respondents on the lowest incomes were most likely to say more money would improve their own quality of life: less than $£ 4160$ : 35 percent $(77), £ 4160<£ 9360$ : 32 percent (141), £9360<£17680: 23 percent (46), £17680+: 23 percent (22) $\left(\chi^{2}(3)=11.330, p<.01\right)$. As one man said:

If people could have about $£ 100$ per week on top of bills - sometimes there is something I would like, such as a regular holiday, or trips - more money to go out for the day and perhaps buy lunch out. . . . I get just over $£ 101$ per week, but when you take the rent and council tax off I end up with about $£ 50$ for everything. (3078 3 0012)

Other areas were mentioned by less than 7 percent: living in a better home or area, having their independence (e.g., being able to drive again, to be able to get out and about), more social roles and activities (including solo activities), having a more positive disposition and society/politics (e.g., government policies on pensions, crime). Some people mentioned practical things.

To have no stairs. (105502)

A wee bit more money to build a downstairs toilet. (109201)

Transport - accessible to people with disabilities, level access at each stop. (101202)

Knowing that it is safe to go out and about. (101801)

To get involved in something, to be part of something. (108301)

Improving quality of life for older people in general —Finally, respondents were asked what single thing would improve the overall quality of life for people of their age. The two most common responses again were to have enough money, better financial circumstances or higher pensions (44 percent), followed by better health (some of these also said better health care) (27 percent). A few mentioned home and neighborhood, social relationships, roles and activities, psychological well-being, independence and society/politics ( $<10$ percent in each case). There were no significant associations with socio-demographic, social, or psychological 
characteristics or circumstances and those who mentioned, or did not mention, these themes, except with reported loneliness and mentioning social relationships as the most important thing that would improve other people's quality of life: 25 percent (4) of those who said they "always" felt lonely mentioned this, in comparison with 8-9 percent (4-30) respectively of those who said they "often" or "sometimes" felt lonely, and 5 percent, 29) of those who said they never felt lonely $\left(\chi^{2}(3)=16.123, p<.001\right)$. A poignant comment was made by one respondent in relation to the distance between many families:

If we could be friends with our own families and keep in touch. (101702)

However, a few said that social inclusion was an issue for wider society.

Greater inclusion of the elderly in society if they wanted. (107702)

Greater tolerance of the aged by the younger generations. (107603)

Some people also said there was still a need for cheaper public transport, and more security (personal safety) to enable people to feel confident going out, especially at night, which also has implications for maintaining social activities and social contacts.

\section{CONCLUSION AND DISCUSSION}

\section{Summary of Main Findings}

The results presented here are unique in providing empirical evidence, based on a nationally representative sample, of older people's views of the constituents of quality of life. In summary, the results presented here show that, while a common core of values were identified by people, there was also a wide range of responses about the meaning of quality of life, what is important, and how quality of life can be improved. In contrast to comparable research based on younger adults, there were no significant differences in the themes raised by age or gender (Bowling, 1995a, 1995b). It appears that once people reach age 65, and are mostly retired from paid work, values and priorities between the sexes converge. While there was considerable consensus on the main constituents of quality of life, different priorities emerged depending on whether people were questioned about the good or bad areas of life quality, priorities, and suggestions for improvements. While having good social relationships was the most commonly mentioned constituent that gave their lives quality, poor health was most often mentioned as the thing that took quality away from their lives. Both were the most often mentioned as the most important area of quality of life overall. Having health, followed by having enough money, were the most often areas mentioned when people were asked about what would improve the quality of their own lives. However, finance 
and then health were most often mentioned as the thing that would most improve the lives of other people their age.

People valued most what they had lost (e.g., health, income). The results also illustrated how areas of quality of life interrelate. For example, retaining independence and social participation is partly dependent on retaining health and adequate finances. These can in turn be influenced by local transport facilities, type of housing, community resources, and social relationships. Overall, respondents enjoyed the flexibility of retirement, and freedom from the time constraints of paid work but this could only be enjoyed if relatively good health was maintained and if people lived in areas which facilitated social relationships, neighborliness, and mobility (via good transport facilities).

\section{Limitations of the Research Design}

The response rate to this survey was within the range expected for a national survey. It is unknown what the non-responders' reasons were for refusal to participate in the study. The respondents were similar in the distribution of their socio-demographic characteristics to the population aged 65 and older in Britain. However, it remains unknown whether the non-respondents differed in other ways (e.g., the responders might be those who were more likely to be socially involved participants generally, or, alternatively those who were the most socially involved might have been too busy to take part in this study).

\section{Implications of the Results for Further Research}

Fry (2000), in her study of quality of life among older adults in Canada, reported that protection of individual rights and choices, and freedom from discrimination were the main themes which respondents rated highly. In comparison, responses from this British sample focused more on everyday issues about relationships, health, finances, and so on. Respondents from both studies emphasized the importance of an active and independent life, the need for employment opportunities, and concerns about crime, but the British sample lagged behind the Canadians in terms of demands for economic and legal guarantees and assurances of their rights. Comparable surveys are needed in the future to document the extent to which future cohorts have adopted more pro-active, demanding attitudes.

People are influenced by their personal history, experiences, education, and the society they live in. The current generation of people aged 50 plus are the next generation of older people and their demands and aspirations may be quite different. They include the post World War II Baby Boomers who will have a higher level of education and higher incomes and most of whom will have occupational pensions with accompanying increased purchasing power. Their expectations are likely to be different from the current generation of older people in Britain who experienced the depression in the 1930s and a World War. Many of this age group left school at 14 , hold no further qualifications, and are reliant 
on a state pension and benefits (Nelson, Murray, Henke, Wiseman, \& Tate, 2001). Longitudinal research is needed to assess both cohort effects and the effects of changing values, or response shift, on quality of life (Sprangers \& Schwartz, 1999).

Researchers have failed to address the complexity and dynamics of quality of life, the interdependency of domains, the distinction between indicator and causal variables (Fayers \& Hand, 2002), potential mediating variables, and age cohort effects (Zizzi, Barry, \& Cochrane, 1998). An appreciation of these issues would lead to more appropriate measurement scales. This is the next step that is needed in quality of life research.

\section{Significance of the Findings}

The results also emphasize that quality of life instruments should focus on far more than the traditional areas of life satisfaction or health and physical functioning. While this emphasis on a broader model of quality of life is not new (Cella \& Tulsky, 1990), many of the themes identified in this study have still been omitted in recently developed models and measures (Skevington, 1999; Skevington, Bradshaw, \& Saxena, 1999; WHOQOL Group, 1993). Apart from scales measuring ability to perform activities of daily living, instrumental activities and mobility, the multifaceted nature of independence, particularly in older age, is generally neglected in the wider measurement literature. Likewise, many of the sub-themes reported in this study have received little attention throughout the quality of life literature - for example, enjoyment of one's home, the importance of the wider community and social capital, and the necessity of access to public transport, or being able to drive and maintain a car, for independence and enjoyment of life in older age.

The significance of the results in this article also lies in the provision of strong empirical evidence on positive areas of life quality in older age, and on the interdependency of these areas of life. Public policy departments (e.g., health care, social care, transport, pensions, the family, environment) tend to regard their own areas in isolation of others, while the promotion of well-being requires that their interdependencies and knock-on effects are understood and taken into account in policy planning.

\section{ACKNOWLEDGMENTS}

We are grateful to ONS Omnibus Survey staff and ONS Qualitative Research Unit, in particular Maureen Kelly, Olwen Rowlands, Jack Eldridge, and Kirsty Deacon for their much appreciated advice and help with designing the questionnaire, for conducting focus groups with older people to inform the questionnaire design, and for sampling and overseeing the Quality of Life Interview and 
processing the data. We are also grateful to Matthew Bond for advice with analysis, ONS interviewers and to the respondents themselves.

\section{REFERENCES}

Andrews, F. M. (Ed.) (1986). Research on the quality of life. Michigan: University of Michigan, Institute for Social Research.

Andrews, F. M., \& Withey, S. B. (1976). Social indicators of well-being: American's perceptions of life quality. New York: Plenum Press.

Baltes, P. B., \& Baltes, M. M. (Eds.) (1990). Successful aging. Perspectives from the behavioural sciences. New York: Cambridge University Press.

Berkman, L. F., \& Glass, T. (2000). Social integration, social networks, social support and health. In L. F. Berkman \& I. Kawachi (Eds.), Social epidemiology (pp. 137-173). Oxford: Oxford University Press.

Bond, J., \& Carstairs, V. (1982). Services for the elderly: A survey of the characteristics and needs of Edinburgh: A population of 5,000,000 old people. Scottish Home and Health Studies No. 42. Edinburgh: Scottish Home and Health Department.

Bowling, A. (1993). The concepts of successful and positive ageing. Family Practice, 10, 449-453.

Bowling, A. (1994). Social networks and support among older people and implications for emotional well-being and psychiatric morbidity. International Review of Psychiatry, 9, 447-459.

Bowling, A. (1995a). What things are important in people's lives? Social Science and Medicine, 41, 1447-1462.

Bowling, A. (1995b). The most important things in life. Comparisons between older and younger population age groups by gender. International Journal of Health Sciences, 6, $169-175$.

Bowling, A. (1996). The effects of illness on quality of life. Journal of Epidemiology and Community Health, 50, 149-155.

Bowling, A. (1997). Measuring health. A review of quality of life measurement scales (2nd ed.). Buckingham: Open University Press.

Bowling, A. (2001). Measuring disease. A review of disease specific quality of life measurement scales (2nd ed.). Buckingham: Open University Press.

Bowling, A., Bannister, D., Sutton, S., Evans, O., \& Windsor, J. (2002). A multidimensional model of quality of life. Ageing and Mental Health, 6, 355-371.

Bowling, A., Farquhar, M., \& Browne, P. (1991). Life satisfaction and associations with social network and support variables in three samples of elderly people. International Journal of Geriatric Psychiatry, 6, 549-566.

Bowling, A., Farquhar, M., \& Grundy, E. (1996). Associations with changes in life satisfaction among three samples of elderly people living at home. International Journal of Geriatric Psychiatry, 11, 1077-1087.

Bowling, A., Farquhar, M., Grundy, E., \& Formby, J. (1993). Changes in life satisfaction over a two and a half year period among very elderly people living in London. Social Science and Medicine, 36, 641-655.

Bowling, A., \& Grundy, E. (1998). Longitudinal studies of social networks and mortality in later life. Review in Clinical Gerontology, 8, 353-361. 
Bowling, A., \& Windsor, J. (2001). Towards the good life. A population survey of dimensions of quality of life. Journal of Happiness Studies, 2, 55-81.

Cella, D. F., \& Tulsky, D. S. (1990). Measuring quality of life today: Methodological aspects. Oncology, 4, 29-38.

Cicero, M. T. (44 BC) (1979). His discourse of old age. Reprinted by Arno Press, PA.

Cooper, K., Arber, S., Fee, L., \& Ginn, J. (1999). The influence of social support and social capital on health: A review and analysis of British data. London: Health Education Authority.

Day, A. T. (1991). Remarkable survivors. Washington, DC: Urban Institute Press.

Farquhar, M. (1995). Elderly people's definitions of quality of life. Social Science and Medicine, 41, 1439-1446.

Fayers, P. M., \& Hand, D. J. (2002). Causal variables, indicator variables and measurement scales: An example from quality of life. Journal of the Royal Statistical Association, 165, Part 2: 1-21.

Fitzpatrick, R. (1999). Assessment of quality of life as an outcome: Finding measurements that reflect individual's priorities (editorial). Quality in Health Care, 8, 1-2.

Fry, P. S. (2000). Whose quality of life is it anyway? Why not ask seniors to tell us about it? International Journal of Aging and Human Development, 50, 361-383.

Garratt, A. M. \& Ruta, D. A. (1999). The Patient Generated Index. In C. R. B. Joyce, C. A. O'Boyle, \& H. McGee (Eds.), Individual quality of life. Approaches to conceptualisation and assessment (pp. 105-118). Amsterdam: Harwood Academic Publishers.

Goldberg, D. P., \& Williams, P. (1988). A user's guide to the General Health Questionnaire. Windsor: NFER-Nelson.

Grundy, E., \& Bowling, A. (1997). The sociology of ageing. In R. Jacoby \& C. Oppenheimer (Eds.), Psychiatry in the elderly (2nd ed., pp. 24-36). Oxford: Oxford University Press.

Hickey, A., O’Boyle, C. A,. McGee, H. M., \& Joyce, C. R. B. (1999). The schedule for the evaluation of individual quality of life. In C. R. B. Joyce, C. A. O'Boyle, \& H. McGee (Eds.), Individual quality of life. Approaches to conceptualisation and assessment (pp. 119-134). Amsterdam: Harwood Academic Publishers.

Kushman, J., \& Lane, S. (1980). A multivariate analysis of factors affecting perceived life satisfaction and psychological well-being among the elderly. Social Science Quarterly, 61, 264-277.

Larson, R. (1978). Thirty years of research on the subjective well-being of older Americans. Journal of Gerontology, 33, 109-125.

Lau, R. R, Hartman, K. A., \& Ware, J. E. (1986). Health as a value: Methodological and theoretical considerations. Health Psychology, 5, 25-43.

Lawton, M. P. (1980). Environment and aging. Monterrey, CA: Brooks Cole.

Lawton, M. P. (1991). A multidimensional view of quality of life in frail elders. In J. E. Birren, J. Lubben, J. Rowe, \& D. Deutchman (Eds.), The concept and measurement of quality of life. New York: New Academic Press.

Lawton, M. P. (1996). Quality of life and affect in later life. In C. Magai, S. H. McFadden, et al. (Eds.), Handbook of emotion, human development, and aging. San Diego, CA: Academic Press.

Lowenthal, M. F., \& Haven, C. (1968). Interaction and adaptation: Intimacy as a critical variable. American Sociology Review, 33, 20-30. 
Maddox, G. (1963). Activity and morale: A longitudinal study of selected elderly subjects. Social Forces, XLII, 195-204.

Markides, K. S., \& Martin, H. W. (1979). A causal model of life satisfaction among the elderly. Journal of Gerontology, 34, 86-93.

Martin, J., Meltzer, H., \& Elliot, D. (1988). The prevalence of disability among adults. OPCS Surveys of Disability in Great Britain. No. 1. London: HMSO.

Maslow, A. (1954). Motivation and personality. Harper: New York.

Nelson, C., Murray, R., Henke, N., Wiseman, O., \& Tate, J. (McKinsey and Company) (2001). Expectations of the 2020 U.K. healthcare system. In Health trends review. Proceedings of a conference held by Her Majesty's Treasury, Health Trends Review Team. Barbican Conference Centre, London 18th and 19th November. London: Her Majesty's Treasury.

Putnam, R. D. (2000). Bowling alone. The collapse and revival of American community. New York: Simon and Schuster.

Rogerson, R. J., Findlay, A. M., Coombes, M. G., \& Morris, A. (1989). Indicators of quality of life. Environment and Planning, 21, 1655-1666.

Roos, N. P., \& Havens, B. (1991). Predictors of successful aging. American Journal of Public Health, 81, 63-68.

Scanlon, T. (1993). Value, desire, and quality of life. In M. C. Nussbaum \& A. Sen (Eds.), The quality of life (pp. 185-200). Oxford: Clarendon Press.

Scheier, M. F., \& Carver, C. S. (1985). Optimism, coping and health: Assessment and implications of generalised outcome expectancies. Health Psychology, 4, 219-247.

Schwarzer, R. (1993). Measurement of perceived self-efficacy: Psychometric scales for cross-cultural research. Berlin: Free University of Berlin, Institute for Psychology.

Sherbourne, C. D., \& Stewart, A. L. (1991). The MOS social support survey. Social Science and Medicine, 32, 705-714.

Skevington, S. M. (1999). Measuring quality of life in Britain: Introducing the WHOQOL-100. Journal of Psychosocial Research, 47, 449-459.

Skevington, S. M, Bradshaw, J., \& Saxena, S. (1999). Selecting national items for the WHOQOL: Conceptual and psychometric considerations. Social Science and Medicine, 48, 473-487.

Spiro, A., \& Bossé, R. (2000). Relations between health-related quality of life and well-being: The gerontologist's new clothes. International Journal of Aging and Human Development, 50, 297-318.

Sprangers, M. A. G., \& Schwartz, C. E. (1999). Integrating response, shift into healthrelated quality of life research: A theoretical model. Social Science and Medicine, 48, 1507-1515.

Sutton S. (1998). How ordinary people in Great Britain perceive the health risks of smoking. Journal of Epidemiology and Community Health, 52, 338-339.

Townsend, P. (1979). Poverty in the United Kingdom. Harmondsworth: Pelican.

Usui, W. M., Thomas, J. K., \& Durig, K. R. (1985). Socio-economic comparisons and life satisfaction of elderly adults. Journal of Gerontology, 40, 110-114.

Walker, A., \& Maltby, T. (1997). Ageing Europe. Buckingham: Open University Press.

Ware, J. E, Snow, K. K., Kosinski, M., \& Gandek, B. (1993). SF-36 Health Survey. Boston, MA: New England Medical Centre. 
306 / BOWLING ET AL.

Wenger, G. C. (1992). Morale in old age: A review of the evidence. International Journal of Geriatric Psychiatry, 7, 699-708.

Wentowski, G. (1981). Reciprocity and the coping strategies of older people: Cultural dimensions of network building. Gerontologist, 21, 600-609.

WHOQOL Group (1993). Measuring quality of life: The development of the World Health Organisation Quality of Life Instrument (WHOQOL). Geneva: World Health Organisation.

Zizzi, A., Barry, M. M., \& Cochrane, R. (1998). A mediational model of quality of life for individuals with severe mental problems. Psychological Medicine, 28, 1221-1230.

Direct reprint requests to:

Anne Bowling, Ph.D.

Dept. of Primary Care and Population Sciences

University College London

Royal Free Campus

Rowland Hill Street

London NW3 2PF

e-mail: abowling@ucl.ac.uk 